\title{
Ethics of Future Doctors in the Process of Teaching Foreign Language
}

\author{
Oksana Isayeva* \\ Candidate of philological sciences, Associate Professor of the Department of Foreign Languages, Danylo Halytskyi Lviv National \\ Medical University, Lviv, Ukraine \\ *Corresponding author: vanivska@inbox.ru
}

Received September 28, 2013; Revised October 10, 2013; Accepted November 26, 2013

\begin{abstract}
The article deals with the problem of implementing professional ethics into higher medical education while teaching foreign languages. In Ukraine professional ethics of doctors encompasses the codes of morality, ethics, deontology and bioethics of major professional issues, providing facts how various professions define, interpret, and enforce ethical behavior. Professional ethics should only be educated in adolescence, in particular, while being a student. Humanity disciplines should be based on the identification of opportunities for education of ethical standards in students. The basic principles of English classes should be the use of individual, pair and group discussions of medical students' about current professional issues, giving students the opportunity to think, to express their own thoughts and ideas and to focus on the content of cultural expression. During practical lessons the teacher should focus on medical ethics, its relationship with medical practice and modern ethics in general. Future doctors should strictly follow the main principles of medical ethics and confidential approach to patients' problems, complaints, diagnosis and treatment.
\end{abstract}

Keywords: ethics, higher professional medical education, foreign languages, humanity disciplines, culture, morality

Cite This Article: Oksana Isayeva, "Ethics of Future Doctors in the Process of Teaching Foreign Language.” American Journal of Educational Research 1, no. 11 (2013): 517-522. doi: 10.12691/education-1-11-10.

\section{Introduction}

Professional education in Ukraine is a core component of the continuing higher medical educational system and represents the integrated hi-tech networking principles and technologies by creating modern attitude to patients, their relatives, life-style and even health. According to the differences between medical and educational systems the teaching methods of theory and methodology of professional education and professional ethics should be distinguished in the system of medical care in the process of teaching foreign languages. Medical students are engaged in a dialogue on the future of professionalism in medical education. The major task of higher education is to familiarize medical students with general life culture, ethics, morality, perception and to ease their socialization, while further professional medical education aims at narrowing the gaps between education and future job. The increasing orientation of the educational system according to human values justifies moral dominant of responsibility, kindness, restraint, moderation, tolerance, and self-esteem as basic personal characteristics of an educated and cultural doctor, i.e. to be able to confidential communication and understanding adoption of the other's opinions [3]. The teaching staff of higher medical educational establishments have "to evaluate experiments on human subjects, the establishment of hospital ethics committees, the expansion of the role of clinician ethicists, and the integration of ethics into many medical school curricula" [11]. Ethics is relevant to every healthcare professional-patient as well as to every teacher-student, as each of them is a person, a human possessing the personality.

In Ukraine students study humanities subjects during first two years at higher medical educational establishments, i.e. the subject "foreign language" is taught during the first year. For the second year medical students study the subject "professional foreign language". First year students have to gain general knowledge in culture, morality, grammar and communicative skills in English. Beginning with the second year, medical students learn special medical literature determining the main ethical principles, bioethics and deontology.

Thus, the system of higher medical education is aimed at contributing to the professional growth of medical students on the basis of their culture, knowledge arrangement, and the development of their skills, practical abilities and modern training technologies. As researcher $\mathrm{V}$. Andreev marks "personal feature characterizes the individual predisposition to behave appropriately in a wide range of life situations" [2]. Professional medical education provides an extensive range of studying options and helps students get a successful start in their future profession. To optimize the process of learning humanities means to improve the quality of learning culture and values of professional communication in modern medical 
students and to promote personal motivation of future doctors at the English classes. The teaching of ethics to medical students has recently become a topic of much importance to all concerned with medical education. However, those most involved, the students themselves, have been consulted very little. Future medical specialists should remember about medical ethics as the system of moral principles that apply values and judgments to the practice of medicine.

\section{Research Methodology}

In Ukraine the progressive expansion of multicultural education determines the adoption of new approaches to the national higher education of young physicians and sets the task of prior development of such moral qualities in medical students as spirituality, creativity, independence, frankness, and respect of different points of view. Ethics education needs to become more reflective about its social and political ethics as it participates in the construction and transmission of medical ethics. It argues for a critical approach to medical ethics and explores the political context in medical schools and some of the peculiar problems in medical ethics education. Teaching staff should focus on importance of unity of vision and purpose in ethics and humanities in order to collaborate and identify how their disciplines advance professionalism. As R. Momeyer observed, "Students frequently arrive in our classrooms with very limited ways of morally engaging problematic situations, by, for instance, appealing to religious dogmas, or a relentless subjectivism and/or relativism, or by privileging - as well enculturated Americans seemingly must, - the exercise of individual autonomy over all other values" [12]. This statement highlights that higher medical education toward professionalism requires transformational change, whereby medical ethics and humanities educators would make explicit the centrality of professionalism to the formation of future physicians.

Therefore, a new European process is being implemented into multicultural national medical educational environment, its main purpose is to create conditions that protect and support the development of each student. Teaching medical students the basic cultural norms and ethics in English as a foreign language is considered to be an integrating and unifying subject for humanities.

Thus, it is expedient to implement appropriate methods and technologies into practice that promote individual and personal approach to the development of social and human adaptation in intercultural learning environment through a variety of activities:

- to activate the process of self-discovery, selfdevelopment, and promote reflection mechanisms;

- to identify the most important needs in medical education and the problems in the organization of pedagogical interaction organization in which everyone has the opportunity to set personal and meaningful life goals for self-realization;

- to find methods, means and forms of adaptation, protection and support of the doctor by means of information, consultation or practical character.

Using these activities in teaching English enables medical students to apply their ethical knowledge into practice, to develop their decision making skills, and reasoning skills in ethical situations. Medical students also need opportunities to learn that their critical thinking skills will be needed in shaping the social policies in their future work.

\section{Discussion and Results}

Medical education is undergoing changes as well as other Ukrainian educational branches, and ethics as an intercultural and international perspective for future doctors is considered to be an active moral position. It is a complex phenomenon determining a person's attitude to the surrounding world and self-attitude. Medical ethics is an inner conviction specifying human activity. Thus, professional ethics is assumed to be only educated in adolescence, in particular, while being a student. This period has its psychological and age peculiarities which are characterized by emotional openness, immaturity, insufficient life experience and the influence of culture, social activity, relatives, friends and other relationships. At this age the feeling of cultural identity of a person starts to form, and interest to questions of cultural preference increases respectively.

Ethics and culture are closely connected and have to be imparted to medical students during teaching humanities. Students' own living position, their increased interest to internal world, the development of reflection, perception, and bioethical norms constitute a special value. The authors state: "In this study a variety of everyday ethics issues were frequently encountered as residents cared for patients. Yet, faculty preceptors infrequently explicitly identified or taught these issues during their interactions with residents. Ethics education is important and residents may regard teaching about the ethics-related issues they actually encounter to be highly relevant. Better understanding of the barriers to teaching is needed in order to promote education about everyday ethics in the out-patient setting” [9].

"Primum non nocere!" means “ First of all - do no harm!” It is a moral principle, which allows choosing options for action in real practical activity of medical professionals, in which the highest degree of benefit and the least degree of harm to the patient would be present. The principle of "do no harm” has become a fundamental ethical requirement for physicians in their professional activities. But the paradox of medical practice is that the achievement of patient's benefit goes through the infliction of a certain (in each case different) degree of harm. "There are patients who cannot be helped, but there are no patients who cannot be harmed" [7].

Therefore, the aim of ethics formation means positive interaction with people, their points of view, outlook, culture, position, orientation and the internal belief defining person's activity, e.g.: you might feel a little bit of discomfort; this might hurt a little but I'll be quick; tell me if it hurts; let me know if it's sore; it will be very quickly; it won't take long; you're doing very well. Ethics as a notion comprises such key structural components as informative, behavioral, emotionally-estimated and communicative which have to be simultaneously developed since they are in close interrelation and interdependence for future doctors' activity. Future doctors should remember about the role of ethics in their 
workplace as it has taken on greater significance and importance.

Doctors' professional ethics gathers together the codes of morality, ethics, deontology and bioethics of major professional issues, providing facts how various professions define, interpret, and enforce ethical behavior, e.g.: explaining the diagnosis: you are suffering from ...; you have ...; you have developed ...; this is why ...; this is mainly because ...; you could try ...; you may find ...; you must keep ...; you should try .... It implies scientific and methodological support for the development and implementation of innovative educational programs in English for skilled professionals. The nature of ethical enquiry is highly compatible with the learning processes of the English language because it should operate within the sphere of medical practice and medical education. The writings of Jürgen Habermas [4] on discourse ethics have also influenced legions of teachers to examine anew the value of a consensus-seeking dialogue that is widely inclusive and highly participatory.

The ancient Greek philosopher Aristotle considered professional ethics as a special branch of moral knowledge. It is also believed that the ancient Greek physician, "father" of medicine Hippocrates developed the first in the history professional code in the form of doctor's oath as a starting point of ethics. This ethical requirement was recorded in the "Oath" by Hippocrates. In the "Oath" Hippocrates said: "Whatever I see or hear in the process of treatment or without it about the people's lives that should not be divulged, I'll keep silent about it, considering such things secret." [5]. The first medical ethics codes for medical practitioners were established by the American Medical Association in 1847, the same year the association was founded. Many professions have a code of ethics that guide individual practitioners' behavior. In the medical profession, these ethics are particularly important, as medical professionals are responsible for the health and recovery of their patients.

Currently, issue in medical ethics is an area of ethics that has particular interest for the general public as well as the medical practitioner. Medical ethics can be traced as general moral philosophy and theology. For physicians it is necessary to learn how to make the most ethical decisions possible from the point of view of private and professional ethics. There are four "basic principles" of medical ethics approach [10]:

- respect for autonomy - the patient has the right to refuse or choose their treatment. (Voluntas aegroti suprema lex).

- beneficence - a practitioner should act in the best interest of the patient. (Salus aegroti suprema lex).

- non-maleficence - "first, do no harm" (Primum non nocere).

- justice - concerns the distribution of scarce health resources, and the decision of who gets what kind of treatment (fairness and equality).

The principles address to the issues of fairness, honesty, and respect for fellows, human beings which arise in interactions between providers and patients. Medical ethics and morality are frequently referred to in conjunction and appear together in many points of view, but they combine to form a cohesive unit, and complement each other. Nevertheless, future doctors should strictly follow the main principles of medical ethics and confidential relationship with patients' problems, complaints, diagnosis and treatment. Medical ethics is closely connected with professional responsibility.

Thus, in Ukraine it is necessary to ensure appropriate ethical training at higher medical educational institutions. It should be noted that block of humanity disciplines should be based on the identification of opportunities for teaching ethical standards to students. Entire educational environment (organization of educational process, teaching staff) of the university should be directed to the development of culture and morality which will play an important role in health care activity. Scientific and technical decisions in healthcare cannot be made in isolation from a framework of ethics and values. Therefore, while teaching a foreign language, a teacher should provide real-world examples of ethical issues and the doctor's duty of professional confidentiality in the workplace using original medical texts for reading and discussing. Such types of texts could give the students insight into the development of sound patterns of behavior with their colleagues, patients, caregivers and their relatives. It is necessary to remember that current cases and key readings provide an interesting, challenging, and practical learning experience for medical students and even future specialists of medical care. Practical experience also gives students possibility to find out to what extent any information shared with or any advice received from a doctor is protected in each patients' case. Three major themes of teaching English related to everyday ethics issues have been identified, concerning:

- the Doctor-Patient Interaction (relationships; communication; shared decision making);

- the Doctor as a Learner (developmental issues; challenges and conflicts associated with training; relationships with colleagues and mentors; interactions with the preceptor);

- the Doctor-System Interaction (financial issues; doctor-system issues; external influences; doctor's frustration related to system issues).

It is possible to assert with certain degree of likelihood that the concept of pedagogical incentive is based on deep humanistic sense. Personality formation of a future physician within the culture-formation aspect, is carried out in the following - to direct, instruct and encourage her/his inner spiritual and moral strength, but at the same time, taking into account the student's age and mental characteristics - consistently reduce the influence of medical and educational factors which cannot be classified as incentives (punishment, threats, administrative pressure). As the founder of Ukrainian pedagogy and didactics K. Ushynskyi noted that: “only the personality can educate a personality, the character can form a character" [8].

Teachers are figures of great significance in medical ethics education, because they are one of the most important factors in forming students' morality and professional character. English teachers have to develop such characters as patience, tolerance, kindness, goodwill and empathy in every student of medical establishments, as educational background mostly points out the phenomena of future achievements in professional activity. One should remember about the importance of teacher's personal qualities at higher medical educational establishment for training of future physicians. The 
following professionally significant qualities and characteristics have been defined: high morality, tolerance, empathy, creativity, scientific conception of the world, developed professional thinking, general and professional culture, etc. The contemporary teacher of higher medical educational institution is characterized by a constant aspiration for creativity, improvement of skills, innovation in professional, as well as spiritual and moral aspects.

Teachers of higher medical education should consciously work on their self-improvement, becoming more successful and integral personalities. Thus, it is necessary to permanently improve their knowledge, to ensure the atmosphere of trust and confidence at their departments and student groups, determining the merits of colleagues and students; to respond to all the demands of society and students, which become incentives to selfimprovement, reasons of everyday life; to enjoy work; to use force and authority tactfully and morally. In that case a teacher can become a model for the students to follow without losing his/her own independence. The greatest effect in preparing future physicians for professional activity will be achieved if the teacher possesses high morality, culture and besides professional knowledge and skills, has enormous spiritual, moral, intellectual and ethical-deontological potential.

During practical lessons the teacher should focus on medical ethics, its interrelation with medical practice and modern ethics in general. The teacher should use an innovative technique of making the process of the text learning more interesting, useful and important by offering medical as well as legal facts from the original literature. The teacher has to provide thorough coverage of all of the themes recommended in the program approved by the Ministry of Health, and in depth analysis of recent decisions, encouraging students to think analytically about the ethics, morality and general aspects of ethics in the context of medicine and to implement them into practice. Therefore, future specialists will have the opportunity to accept seriously the fact that it is time for students to try a new approach to studying and fostering of professional and business ethics.

Future doctor is a holder of high moral qualities having profound ethical knowledge, possessing the method of ethical and aesthetic communication process. Therefore, cultural, moral and ethical formation of a personality is an important sphere of medical student's self-improvement. There are lots of values for future medical specialists but they do not give answers as to how to handle a particular situation, but provide a useful framework for understanding conflicts. Many so-called "ethical conflicts" in medical ethics are traceable back to a lack of communication. Communication breakdowns between patients and their healthcare team, between family members, or between members of the medical community, can all lead to disagreements, patient's disbelief, frustration and strong emotions. These breakdowns should be remedied, and many apparently insurmountable "ethics" problems can be solved with open lines of communication. Formation of sociocultural component in teaching professional English communication is a phased process of mastering professional and communicative skills, first learnt and then accurately combined with certain verbal actions of professional and cultural character. This component is the main principle in the development of contemporary educational processes, namely competence approach and cultural communicative competence.

In modern medicine under medical confidentiality one can understand "all the information obtained from the patient or revealed during a medical examination or treatment that cannot be disclosed without the consent of the patient" [1]. "From an ethical point of view, the concept of "medical confidentiality" is the concretization of humanism principle in medicine, respect for human dignity, the patient's legal rights as well as the spread of “doing no harm" principle into all aspects of life, patient's lifestyle, patient's well-being, which can be harmed by the health care provider's disclosure of confidential professional information" [6]. Confidentiality is an important issue in primary care ethics, where physicians care for many patients from the same family and community, and where the third part often request information from the considerable medical database typically gathered in primary health care. Confidentiality is generally applied to conversations between doctors and patients. This concept is commonly known as a patientphysician privilege. Legal protections prevent physicians from revealing their discussions with patients, even under oath in court.

Being a good healthcare professional requires competency in ethics as it stimulates a frank discussion on how consent is obtained and what can be done to improve the quality of consent. The concept of "medical confidentiality" is narrower, as it only concerns doctor's activities. The concept of "medical secrecy" reflects the ethical requirements that apply to all health care professionals, including doctors. As a doctor is the main character in the process of patient's diagnostics and treatment, maintenance of "confidentiality" requires more responsibility [6]. The ethical fundamentals for consent to medical treatment, methods of ethical analysis, professional responsibility and codes of ethics, security, risks, and liabilities should be approached in the context of the healthcare professional-patient relationship at every practical English lesson e.g.: the prognosis of a disease: you'll recover more quickly ...; I'm going to have you admitted to ...; it would be good ...; don't hesitate to ...; we can never be absolutely certain about ...; hopefully we can ...; I strongly suggest you ...; I expect the treatment will ...; you should remain optimistic ...; do you think you could ....

It can be used individually or in small groups and takes a problem-based learning approach to the complex legal and ethical issues raised by scenarios. These are based on real cases that clearly demonstrate the problems arising from recent medical advancements. Ethics is taught as a requirement of the medical course introducing it into each new theme and demonstrating possible situations. Students should improve their ability to analyze ethical issues and find the cases stimulating, engaging and interesting. Thus, the basic principles of English classes should be the use of individual, pair and group discussions by medical students of current professional issues; giving students the opportunity to think, to express their own thoughts and ideas and to focus on the content of cultural expression.

However, in Ukraine at higher medical educational establishments the studying process is sometimes limited 
to simple text retelling from the textbook: mastering of knowledge occurs through the sample and demonstration, culminating in a more or less conscious understanding and memorizing of the considered material. Explanatory type of the studying process, in which students acquire readyto-use knowledge, does not correspond to modern study theory. To some extent, it inhibits the development of independent thinking and students' creative cognitive activity. Therefore, it is necessary to teach every student to think independently and creatively, to act in unusual situations and solve a variety of problems.

Doctors have the duty to care for the sick and injured, even under threat, ethnic origin, nationality, or political affiliation addressing consent and communication, privacy, examination of patients who lack decision-making capacity, and use of chaperones. But patients differ in their perception of what is required during a medical examination, particularly if the patient comes from a different background. The presence of a chaperone is one way to minimize complaints being made against doctors.

As health professionals, physicians have a key role to play in providing high quality care to all patients without discrimination, preventing and reporting acts of torture and ill treatment that constitute human rights violations. Physicians are also often victims of human rights violations, especially when they act on behalf of the human rights of their patients. Thus, classic English textbook should focus on current medical problems, their relationships with medical practice and modern ethics. Specifically studying "English" and "professional English" at higher medical educational establishments future doctors will:

- clarify the meaning and significance of key ethical concepts;

- outline important types of ethical theory, and their relevance to medical ethics;

- offer a conceptual framework useful for ethical analysis of medical and moral problems in a variety of professional contexts;

- train the skills of ethical behavior and ethics of communication;

- give opportunities to participants - under supportive conditions - to articulate their current medical and moral attitudes, and explore reasonable arguments that challenge their existing assumptions and ethical stances.

In Ukraine humanities disciplines are intended to cater for medical, nursing and allied professionals and administrators who feel the need for an opportunity to review and update their thinking about ethical and moral issues, including medical and nursing teachers, nurses, GPs, consultants, members of ethics committees, hospital administrators, and officials in government departments with responsibilities for health care. They consist of a series of lectures, practical classes, seminars followed by small and large group discussions, which focus on the problems and issues raised by the lecturers and include presentation of arguments opposed to the position actually held by course members, in the context of a particular case. Teaching staff of higher medical institutions argues that improvement of the ethics and humanities-based knowledge and skills, and conduct that fosters professionalism should enhance patient care and be evaluated for its distinctive contributions to practical educational processes aimed at producing this outcome.

\section{Conclusion}

On the basis of our research the conclusion can be made about the importance of teaching English to future physicians, since it helps to acquaint them with different ways of thinking about ethical problems, put their ethical thinking into perspective and relate to present-day healthcare issues. Each practical lesson should be well organized and enjoyable which allows future doctors to begin to understand the ethical process in their day-to-day practice providing a sound theoretical grounding, supported, reinforced and developed through open and productive discussion of practical issues. Theoretical material as an excellent networking opportunity should be fruitful and thought-provoking giving rare opportunity to spend time on reflecting and discussing as well as on learning. The students should be able to know about ethical dilemmas they can be face during their studies and as future practitioners, to be better prepared to provide good reasons for choices made affecting patients and society, to understand the norms and values that govern medical and health practice, to know about ethical questions discussed and to reflect critically on their own current and future practice.

\section{Recommendation}

Thus, humanities disciplines are considered to be one of the best courses for bringing together widely different medical students with common needs in disciplines teaching something for everyone. We believe that the main task in teaching English to medical students is to encourage an active independent thinking and systematic cultivation, to be proactive and able to solve problems creatively. Organizing and conducting training seminars for teaching staff of higher medical institutions will be useful and important in providing successful training for future doctors during English lessons. Regardless of how one explains the allure of relativism, what is clear is that undergraduates need to develop skills and abilities in critical thinking if they are to be able to make wellconsidered judgments, which are inevitable and necessary in doctors' life.

English teachers in general and medical ethics teachers in particular, have not been efficient enough in students' moral development. Therefore, short-term professional teaching courses on medical ethics and active teaching methods are suggested to be held for all medical teachers at higher educational establishments. Besides, all teachers are recommended to be obliged to put those medical ethics principles into practice, as behavioural models facilitate moral and professional development of the students.

\section{References}

[1] Akopov, V.I, Legal support of professional nurses, Fundamentals of health law, Moscow, 2005, 234.

[2] Andreev, V.I, Pedagogy: A training course for creative selfdevelopment, Kazan, 2004, 608. 
[3] Griniova, V.M, Formation of pedagogical culture in a future teacher, Theoretical and methodical aspects, Kharkiv, 1998, 300.

[4] Habermas, J, Moral consciousness and communicative action, MA: MIT Press, Cambridge, 1995, 229.

[5] Hippocrates, Oath. The law about the doctor. Nastavleniya, Minsk, 1998, 10-11.

[6] Ivanyushkin, A.Ya., Khetagurova, A.K, History and Ethics of Nursing, Manual, Moscow, 2003, 132.

[7] Rigelman, Richard K, How to avoid medical errors, Moscow, 1994, 203.

[8] Ushinskyi, K.D, Theoretical Problems of education and training, Selected pedagogical publications in 2 volumes, Kyiv, 1983, Vol. 1, 99-100.
[9] Carrese, J.A., McDonald, E.L., Moon, M., Taylor, H.A., Khaira, K., Catherine Beach, M. and Hughes, M.T, "Everyday ethics in internal medicine resident clinic: an opportunity to teach," Medical Education, 45 (7), 712-721, June 2011.

[10] Gillon, R, "Medical ethics: four principles plus attention to scope,” British Medical Journal, 309, 184-188, July, 1994.

[11] Lakhan, S.E., Hamlat, E., McNamee, T., Laird, C, "Time for a unified approach to medical ethics," Philosophy, Ethics, and Humanities in Medicine, 4 (13), September, 2009.

[12] Momeyer, R, "What conception of moral truth works in bioethics?" Journal of Medicine and Philosophy, 27 (4), 403-416, 2002. 